\title{
THE EFFECTIVENESS OF MINDFULNESS-BASED BEHAVIOR - COGNITIVE THERAPY IN REDUCING SYMPTOMS OF DEPRESSION IN PEOPLE WITH PERSISTENT DEPRESSION
}

\author{
Nazli Rajabpouranvar \\ Master Of Science Candidate, Faculty of Psychology and Education, Kharazmi University, Iran \\ Mohammad Hatami \\ Assistant Professor, Faculty of Psychology and Education, Kharazmi University, Tehran, Iran \\ Hadi Hashemi Rezini \\ Assistant Professor, Faculty of Psychology and Education, Kharazmi University, Tehran, Iran
}

\begin{abstract}
Introduction: persistent depression disorder is a common problem and mindfulness-based cognitivebehavioral therapy has considered as effective treatments in this field. Objective: The aim of this study was to assess the effectiveness of mindfulness-based behavior - cognitive therapy in reducing symptoms of depression in people with persistent depression. Method: Two patients with persistent depression were selected through convenience sampling. Each six times by the mindfulness questionnaire (FFMQ) Bauer, emotion regulation difficulties questionnaire (DERS) and Beck Depression Inventory (BDI-II) were evaluated. The study use single participants multiple baselines, the data collected using repeated measures analysis and data analysis using graphs were analyzed. Formula cure rate and recovery detection criteria for judging the recovery rate was applied. Results: participants with persistent depressive disorder with high percentages of recovery in the post-treatment and 30-day follow-up study proved its effectiveness in all the variables. Conclusion: Mindfulness-based behavior-cognitive therapy in reducing symptoms of depression in people with persistent depression is effective. Therefore, clinicians should attend it more.
\end{abstract}

Keywords: Cognitive therapy, mindfulness, Cognitive emotion, persistent depression disorder

\section{INTRODUCTION}

According to the definition of Diagnostic and statical manual of Mental disorder (DSM5)is a highly prevalent chronic dysthymic mood disorder, about 5 to 6 percent of all people living with the disease. According to the criteria Diagnostic and Statistical Manual of Mental Disorders- Five Edition (DSM-V) states of low self-esteem, feelings of inadequacy, feelings of hopelessness or pessimism and misery, social isolation, decreased activity and performance, chronic fatigue and sense of irritability or excessive anger as the characteristics of persons with mental disorder is named continuous depression [1]. Persistent depressive disorder is common in the general population and consisted disorders in studies Bagheri Yazdi et al (1992) with 5.25, Afshari Monfared et al (1997) as the most common mental disorders with 3.5 percent have been reported [3-4]. In addition, study Noorbala et al (2001) also persistent depression as one of the most common psychiatric disorders listed. Some epidemiological studies of the prevalence of clinical depression in most Western countries shows as three and a half percent in women and sixteen point seven percent of men in the country are suffering from dysthymia. Mindfulness helps the patient to understand that negative emotions may occur, but they are not part of the permanent character. It also allows a person to be involuntarily rather than to events and hurried answer, thinking and pondering the answer. Mindfulness is a way to a better life; relieve suffering and Ghana, and a significant part of life [4]. 
In emotional regulation mechanisms, it is underlying mood disorders and anxiety. A review of Diagnostic and Statistical Manual of Mental Disorders- Five Edition was clear 52 percent of the disorders axis I and $100 \%$ axis II disorders covering the deficits in emotion regulation.

Persistent depressive disorder occurred in people who have a relatively normal life in society. In addition, psychiatric clinics with symptoms such as impulsivity are not as common as stress, high anxiety, low mood, distraction and impatience (DSM-V) is widely seen in everyday life. According to the diagnostic criteria for DSM-V is the most common feature of depression is persistent presence of depressed mood most of the day and on most days. Chronic depression is a disorder characterized by feelings of inadequacy, guilt, irritability and anger, isolation from society, loss of interest, lack of activity and associated loss of productivity. According to the diagnostic criteria for DSM-V is the most common feature of depression is persistent presence of depressed mood most of the day and on most days. Chronic dysthymic disorder with feelings of inadequacy, guilt, irritability, anger, isolation from society, loss, interests, inactivity and lack of productivity associated. Prior to 1980, the majority of patients who suffer from dysthymia know today are depressive neurosis with depression also called neurotic depression; until in 1980 the so-called dysthymia means TIFF (dysthymia) was established [5]. The major complaint of people with dysthymia is persistent depression in most of their lives. In most cases, the disorder and early onset in childhood or adolescence began. Lower starting age from 21 to 25 years is directly related to the chronic progression of chronic depressive disorder in patients with dysthymic may be all sorts of psychiatric drugs, antidepressants and consume illegal substances [6].

Mindfulness-based cognitive therapy based on a theoretical model that factors that contribute to vulnerability to relapse of major depression and the way that cognitive therapy reduces the vulnerability described. Mindfulness-based cognitive therapy is as a process of engaging in a form of non-judgmental experience the present moment [7], largely in the treatment of psychological symptoms such as depression and anxiety spectrum disorders and combined. Studies of the outcomes of the effectiveness of mindfulness-based cognitive therapy for depression and anxiety have supported. Mindfulness-based cognitive therapy involves several different techniques that are derived from the mechanisms of mindfulness. Researchers classified symptoms of anxiety and depression in four general categories [8-9]:

- PUBLIC concern: that both depression and anxiety can be found out:

- PUBLIC concerns in this category include the negative impact of depression and specific symptoms of depression (e.g., self-criticism and feelings of worthlessness).

- Anxiety, general anxiety factors including the negative impact of specific symptoms associated with mood disorders, anxiety (such as worry).

- Dounick depression: a slight positive impact and lack of interest is determined and dedicated to depression.

- Arousal depression that is characterized by physiological arousal, anxiety is specific [9].

That's how different assumptions mindfulness-based cognitive therapy for depression and anxiety symptoms in the form of differentiation of the four categories (depression - public concern, anxiety General anxiety, anxiety and arousal depression) are related, can be more targeted treatments and more patients with different symptoms protests, and lead. Mindfulness-based cognitive therapy has five common mechanisms [10-11]:

- Describing the ability to express inner experiences with words

- Viewing: thoughtful process or due to internal and external experiences acting with consciousness: the current activities to address current and often function automatically compared.

- Lack of judgment: the admission of non-evaluative comments about the thoughts and feelings

- Lack of reactivity: allowing entry and exit of thoughts and feelings without reacting or repair them

Submit Date: 10.05.2016, Acceptance Date: 25.06.2016, DOI NO: 10.7456/1060JSE/039

Copyright (C) The Turkish Online Journal of Design, Art and Communication 
Coffey, Hartman \& Fredrickso (2010) found a significant component of mindfulness-based cognitive therapy (which is conceptually similar to the observer) is associated with increased psychological concerns. One explanation could be that increased attention to the excitement associated with incorrect judgments of the characteristics of people with psychological symptoms [12].

Bernstein et al studies have shown that increasing mindfulness-based cognitive therapy skills training reduces anxiety and depression [13]. Mindfulness training directly related to training people for their ideas and passions decentralization without avoidance, denial or repression of information, closes observation of the phenomenon, and therefore avoids inhibition of experimental and non-judgmental acceptance inquisitive and lack of response to this phenomenon train. Based MBCT, intentional focus on thoughts, emotions, and feelings in this way, a lot of attention to the person's ability to process, so are less able to remain champ.

Segal et al (2002) there is a distinction between doing mode and being mode. Doing mode includes the recognition of the difference between how things and how we want to be. Such differences, negative emotions and thought patterns to find ways to reduce the difference launch. When it can be done constructive measures, this state of mind is adaptive and can lead to the development of many important goals. However, when nothing done to change the situation problematic (For example, when mourning the loss of a spouse or couple), this useless and depressed mental state can be born. Much of the attention on analyzing past mistakes over time, predict the future, and will focus the search for solutions; however, if solutions are not found, it could lead to a pervasive sense of dissatisfaction. Champ in this way, probably underlying negative emotional states [1].

So far, many studies have shown the effectiveness of MBCT. For example, the first clinical trial of MBCT (Teasdale et al., 2000), with the aim of responding to the question whether MBCT Add to current treatment (TAU) can reduce the recurrence rate was depressed or not. For this purpose, 145 patients recruited and randomly assigned into one of two groups MBCT or TAU. Among patients who already lived in the period of partial recovery, in the past were spent at least two periods of depression and for 3 months before entering the trial stopped taking antidepressant medication were selected. One-year followup results showed that for patients with a history of depression three or more, $40 \%$ of MBCT and $66 \%$ for standard treatment, reducing recurrence and $39 \%$ had experienced an average effect size [14].

\section{THE MECHANISMS UNDERLYING THE EFFECT OF EXERCISE MINDFULNESS}

Reload mechanisms underlying the effect of exercise is important mindfulness as a base to explore the future use of these strategies provides important gaps in our current understanding highlighted. This includes the presence of mind "regarding a particular way: on purpose, in the present moment, without judgment" is frequently quoted in the literature. It briefly outlines some of the basic psychological processes of speech to emphasize the therapeutic activity of the mind, and so, we use this expression as a framework to explore and identify these mechanisms.

\section{Attentions to special method}

According to the first procedure requires notification of the matter that is, monitoring the spotlight. In cognitive psychology, thought processes monitoring process, including monitoring the spotlight "metacognition" is called. This monitoring is a necessary condition to lead active, but may have their interests. Metacognitive processes are leading to a growing decentralization of thinking, so that thoughts rather than direct representation of reality is necessarily transient mental events are perceived, has become a form of meta-cognitive insight [15].

\section{Attentions to the target and in the present moment}

This form of targeted, including guidance attention regarding the experience of the present moment. Exercise habits to maintain due to the awareness of the present moment deviate from this 
increase. Alternatively, rumination about the past and future mental imagery may be recognized quickly and sustainability. Mindfulness can be motivated not only by paying attention to the present moment but by letting the experience of the present moment to fill out the "space suit" provide benefits to be reduced so that divert attention away from the present moment. Interventions presence of mind recognizes experiences and future key functions in the treatment of cognitive processing. However, worries and concerns that a common feature of OCD cases rarely have long-term benefits and psychopathology usually continues or intensifies. Mindfulness training on rumination as a solution-focused strategy emphasizes, this method is a step change in terms of processing is based on objective and causing inhibition is unnecessary in the context of a detailed process [15].

Attentions to the present moment are the ability to maintain focus as much as possible. This attention, pay attention to negative emotions, physical sensations, thoughts and disturbing images involves building. This is in contrast to experimental avoiding confusion or distraction from the experience maker. Such avoidance or distraction, when related to temporary stress can be emotional response and appropriate, but over the longer term, suffering or distress is severe maladaptive response. This is consistent with evidence suggests that trying to control cognition and affect, such as the suppression of thought and avoidance coping, consultants predicts poorer long-term outcome [16-21-22]. This decrease avoidance and reactivity to emotion and cognition "negative" grounds for exposure, and provides acceptance of these experiences [12]. The mechanism of desensitization reduced negative emotion and psychological health improves [17].

\section{Attentions without judging}

Hypothetical mechanisms that take the benefits of practicing mindfulness decline in the use of verbal language assessment. Making judgments about a person's experiences as a tendency to amplify its effects to be considered. Mindfulness teaches us instead of evaluating our emotional and cognitive experiences, just to look at them. Mindfulness classified habits by reducing the two categories of experience, as instrumental to strengthen and adapt behavioral and cognitive actions will be considered. This increasing "cognitive flexibility" (Roemer and Oursilo, 2003) increased openness to experience, and the tendency to label some experiences as "the enemy" reduced. This non-judgmental philosophy helps people in their problems [17-20].

\section{Research Plan}

This study is a single subject multiple baselines design that in order to assess the impact of mindfulnessbased cognitive therapy is performed. Single subject study has a long history in psychology [1], in fact, as alternative for case study method is created. Although a case study in clinical psychology is very importance, there are many explanations for many problems including facing results. In addition, the main problem case study can be considered as generalization of the results obtained [18-19]. In addition, in method contrast to group method focuses average and therefore are not considered personal information, the necessary information about the impact of independent variables or experimental method on all subjects [1]. For this reason, given the positive, single-subject experimental designs (like a relative control over experimental conditions, continuous measurement, and baseline measurement), single-subject experimental design was used in this study. The study population included all patients of chronic depressive disorder at 6 months of 2015 attended in Mehregan Counseling and Psychotherapy Clinic. The sample available sample of patients who referred to Mehregan Counseling and Psychotherapy Clinic with a diagnosis of chronic depression in the first six months of 2015 took place. Among patients referred to the clinic, 3 patients with chronic depressive disorder were selected by convenience sampling method and by mindfulness-based cognitive therapy intervention treated. In this study, after the diagnosis of chronic depression, according to the therapist was found and then obtain patient consent and explain the project to them, in terms of our patients to receive treatment, treated by mindfulness-based cognitive therapy intervention. Participants in the study were treated for 8 sessions of 90 minutes. At baseline, all patients have completed their action research tools. Then the participants were determined intervention in the 
meetings of the second, fourth, sixth, at the end posttest after intervention and one month after posttest, follow up treatment performed.

\section{Research Tools}

- Structured Clinical Interview for axis disorders (SCID-I) I

- Beck Depression Inventory - Second Edition (BDI- II)

- Bauer et al Mindfulness questionnaire (FFMQ)

- Cognitive emotion regulation questionnaire

Treatment used in this study was applied individually.

Treatment program were presented in 8 sessions and topics, exercises and homework session of Mindfulness-Based Cognitive Therapy corresponding treatment of the Practical Guide (Segal, Williams, and Teasdale, translated by Mohammad Khani et al., 2007), used.

\section{The method of data analysis}

In the present study to analyze the data, charts and review the impact, coefficients were used. Also, use the following formula to calculate the recovery percentage changes are:

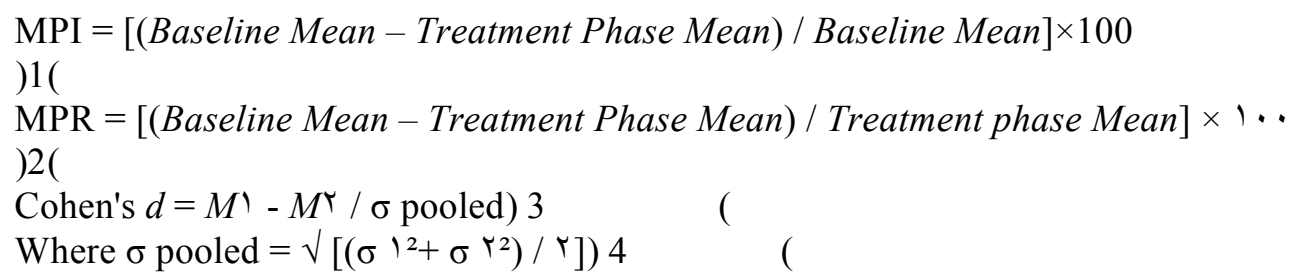

In this formula MPI cure rate, MPR percent reduce in scores and cohens shows variability rate.

The index respectively process changes, slope, show variability. Formula of cure percent is one method of measuring the progress of client is targeted at reducing problems. The formula used by Blanchard and Schwars first [21].

In Formula percent recovery, individual score in pretest and post-test scores of individual subtract and make sure it is divided pretest score. At least 50 percent results are significant clinically.

\section{RESEARCH QUESTIONS AND OBJECTIVES}

In this study, we are looking at the effectiveness of mindfulness in reducing persistent depression using medical practices of mindfulness-based cognitive behavioral therapy, as third wave is valid treatments from psychotherapy that has done in this research area. The question for us is whether mindfulness-based cognitive-behavioral therapy (MBCT) in reducing the symptoms of dysthymic patients with persistent depression is effective.

Persistent depressive disorder is prevalent in society and that many people out there suffer this disorder and its consequences in everyday life. This disorder overlap with other psychiatric disorders such as anxiety disorders is high. Chronic depression on the bottom of mindfulness, cognitive disorder is effective. Generally, the disorder effect on cognitive, emotional, physiological, behavioral and motivational person functions. The latest research in the field of treatment of chronic persistent depressive disorder and low current treatments for psychological response and a history of previous treatment failure point [22]. Due to the use of different psychological treatments so far the researchers examined and on the disorder and the effectiveness of their low and given the high prevalence of the disorder among people and its impact on different aspects of life, in this study, through mindfulness-based cognitive-behavioral therapy to alleviate the symptoms of depression.

The aim of this study was to evaluate the effectiveness of mindfulness-based cognitive-behavioral therapy (MBCT) in mindfulness and cognitive emotion regulation in patients with continuous depression. In this study, it is assumed that: 
Mindfulness-based cognitive-behavioral therapy on mindfulness patients with persistent depression is effective.

Mindfulness-based cognitive-behavioral therapy in reducing persistent depression is effective in patients with persistent depression.

\section{RESULTS}

In this section, results are presented in tables and graphs. All subjects underwent 8 sessions of therapeutic treatment known as mindfulness-based cognitive therapy (MBCT) received. Demographic characteristics mentioned in the first and percent recovery factor and stage effects and Cohen baseline, the mean treatment sessions (second session, after the fourth, sixth session, after treatment) 30-day follow-up period presented.

Demographic variables are summarized in Table 1 have been reported and scores and the results of each participants depression at baseline meetings, second, fourth, sixth, after 30 days of treatment and followup, along with the percent recovery factor and Cohen, the tables and related charts are examined separately.

Table 1. Demographic data of subjects participating in this research

\begin{tabular}{|l|l|l|l|l|l|l|}
\hline Subjects & Age & Gender & Education & Job & $\begin{array}{l}\text { marital } \\
\text { status }\end{array}$ & $\begin{array}{l}\text { Previous or } \\
\text { current } \\
\text { treatment }\end{array}$ \\
\hline Subjects 1 & 35 & Male & Bachelor & Employee & Married & No \\
\hline Subjects 2 & 42 & Female & Bachelor & Employee & Married & No \\
\hline Subjects 3 & 37 & Male & Bachelor & Employee & Married & No \\
\hline
\end{tabular}

As Table 1 shows, subjects of both genders in the age range 30 to 40 years are demographic variables every three undergraduate education, marital status, all three men were married in demographic variables and 3 subjects had no history of drug therapy.

To assess depression in patients with chronic depression, the Beck Depression Inventory (BDI) was used.

Table 2: scores of participants with persistent depression, Beck Depression scale stage, baseline, during treatment, after treatment, follow-up and effectiveness

\begin{tabular}{|c|c|c|c|c|c|c|c|c|c|c|c|c|c|c|}
\hline $\begin{array}{l}\text { Multi } \\
\text { plier } \\
\text { effec } \\
\mathrm{t} \\
\text { follo } \\
\text { w-up } \\
\text { meeti } \\
\text { ng }\end{array}$ & $\begin{array}{l}\text { Cohe } \\
n \\
\text { coeffi } \\
\text { cient } \\
\text { follo } \\
\text { w-up } \\
\text { meeti } \\
\text { ng }\end{array}$ & $\begin{array}{l}\text { The } \\
\text { averag } \\
\text { e } \\
\text { impact } \\
\text { factor } \\
\text { interv } \\
\text { ention } \\
\mathrm{s}\end{array}$ & $\begin{array}{l}\text { Cohen } \\
\text { coeffic } \\
\text { ient } \\
\text { Avera } \\
\text { ge } \\
\text { interve } \\
\text { ntions }\end{array}$ & & $\begin{array}{l}\text { duct } \\
\text { in } \\
\text { ores } \\
\text { st } \\
\text { atme }\end{array}$ & $\begin{array}{l}\mathrm{C} \\
\mathrm{u} \\
\mathrm{re} \\
\mathrm{ra} \\
\mathrm{te}\end{array}$ & $\begin{array}{l}\text { Cure } \\
\text { rate } \\
\text { post } \\
\text { treat } \\
\text { ment }\end{array}$ & $\begin{array}{l}\text { Avera } \\
\text { ge } \\
\text { interv } \\
\text { ention } \\
\text { s }\end{array}$ & $\begin{array}{l}\text { post } \\
\text { treat } \\
\text { ment }\end{array}$ & $\begin{array}{l}\text { Sixt } \\
\mathrm{h} \\
\text { Sess } \\
\text { ion }\end{array}$ & $\begin{array}{l}\text { four } \\
\text { th } \\
\text { Sess } \\
\text { ion }\end{array}$ & $\begin{array}{l}\text { sec } \\
\text { ond } \\
\text { sess } \\
\text { ion } \\
\text { and } \\
\text { thir } \\
\text { d }\end{array}$ & $\begin{array}{c}\text { Ba } \\
\text { seli } \\
\text { ne }\end{array}$ & $\begin{array}{l}\text { Subj } \\
\text { ects }\end{array}$ \\
\hline $\begin{array}{c}0.9 \\
9\end{array}$ & 35 & 0.83 & 3.08 & $\begin{array}{c}5.1 \\
4\end{array}$ & $\begin{array}{l}8 \\
4\end{array}$ & 8 & 14.1 & 7 & 8 & 11 & 23 & & 34 & 1 \\
\hline $\begin{array}{c}0.9 \\
9 \\
\end{array}$ & 26 & 0.72 & 2.11 & $\begin{array}{c}2.8 \\
8\end{array}$ & $\begin{array}{l}7 \\
4 \\
\end{array}$ & 9 & 15.7 & 9 & 12 & 15 & 21 & & 26 & 2 \\
\hline $\begin{array}{c}0.9 \\
9 \\
\end{array}$ & 27 & 0.78 & 2.53 & $\begin{array}{c}4.3 \\
3 \\
\end{array}$ & $\begin{array}{l}8 \\
1 \\
\end{array}$ & 7 & 11.7 & 6 & 10 & 10 & 16 & & 22 & 3 \\
\hline
\end{tabular}

According to what can be seen in Table 2. Total data based on data obtained suggest MBCT may decrease symptoms of depression. According to the results, subjects in the first and third round scores improved after treatment in full (less than 8) and the second participant in stage after treatment improved in relative 
(less than 14) are placed. As well as the Beck Depression Inventory scores in three subjects decreased during this reduction until the end of the third subjects continue have meetings and to follow-up session and remained unchanged for the second participant and a small increase for the first participant (a score). That it shows the effectiveness of MBCT in reducing depression symptoms and it can be based on recovery and the effect size obtained in the Beck Depression Inventory\% respectively $81,74,84$ recovery and the effect size $0.78,0.72,0.83$ concluded. Since the cure rate over 50 and shows the effectiveness of the treatment effect size of 0.8 , so based on the percentage of recovery and the size of the effect of this scale can be concluded that MBCT treatment effectiveness is good. Of course, as Table 2 shows the multiplier effect of the participants of the second and third quorum is not reached and the effectiveness of, respectively, $0.78,0.72$ that is close to 0.8 , but the trend of declining grades in this area during therapy sessions and after treatment show the effectiveness of MBCT in this area.

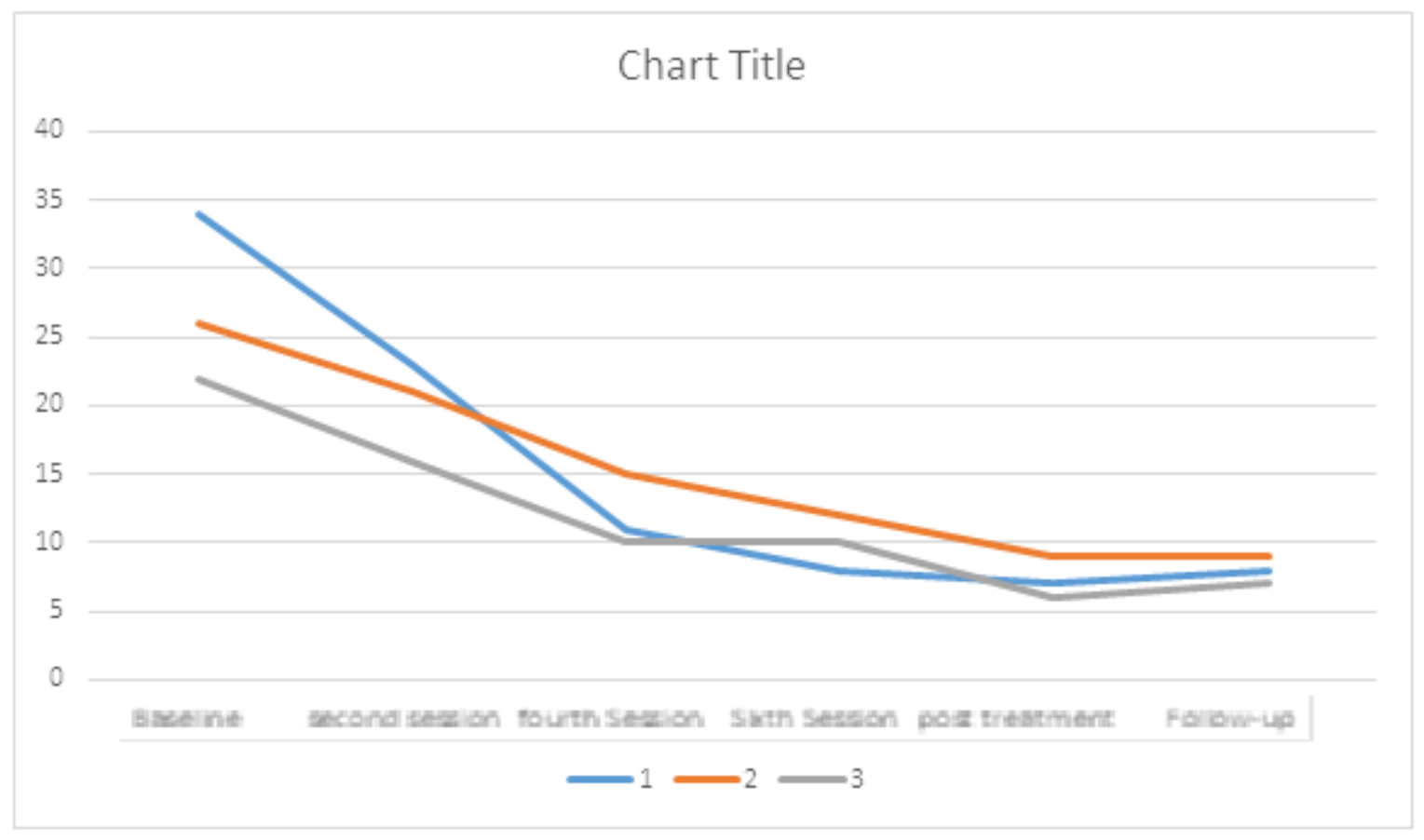

Chart 1: Show changes related depressive symptoms in patients with persistent depression on scores obtained in the Beck Depression Inventory

According to Chart 1 lower scores in all three subjects from the baseline to post-treatment session, even keep track of two months for the second, and third is quite evident subjects. The changes to the first participant until the end of treatment decreased, so that test score of 34 to 7 shifted and put him in the perfect improved and even increase his score in a follow-up meeting him in this field is kept still. The second subject during therapy sessions show a steady trend for lower scores and this trend has been maintained track, that's why he score the same score at follow-up meeting after meeting, and no treatment has not changed. Trends in scores have been declining at a steady subject 3 and this loss to follow-up session and as can be seen the participants score 2 at baseline 7 in the follow-up meeting has been improved and completely put him in the field.

\section{CONCLUSION}

According to what can be seen in Table 2. Total data based on data obtained suggest MBCT may decrease symptoms of depression. According to the results, subjects in the first and third round scores improved 
after treatment in full (less than 8) and the second participant in the post-treatment improved the relative fall in the area. Based on the recovery and the size of the effect is obtained, we conclude that MBCT treatment effectiveness is good.

These findings are consistent with the findings of Kinglston et al., (2007) suggest that MBCT treatment can be an effective treatment for depression symptoms remained. The study showed that this treatment is also effective in reducing depressive persistent symptoms. Research Kinglston et al demonstrated the results obtained in follow-up at one month after therapy sessions, and remain the subjects of important life skills learned in their positions. These findings is consistent with the results of research Brown and Ryan, (2003) showed that mindfulness as a trait associated with fewer depressive symptoms, [11]. Teasdale (1999), the main purpose of using mindfulness to help depressed patients, achieving a way to resist the signs of depression seeks to change people's perception of the current situation and the desired situation to set off. Rumination is indicative of a process contrary to the mind and includes a focus on passive emotions, especially negative emotions, which is inconsistent with the countless features such as DAS, despair and neurosis is relevant and represents a vulnerability factor for depression is persistent, it seems mindfulness neutralizes these features [13]. The present study is the first research of its kind in the context of assessing the effectiveness of mindfulness-based cognitive-behavioral therapy on patients with persistent depressive disorder (Dysthymia) is done. Therefore, this research preliminary findings about the effectiveness of this treatment available to researchers and inspires further research in this field.

\section{REFERENCES}

1. Segal, Zindell; Teasdale, John; Williams, Mark. (2002). Practical Guide to Mindfulness Based Cognitive Therapy.

2. Mohammad Khani, SH; Khanzadeh, Mustafa; Saeidian, M. (2013). Factor structure and psychometric characteristics on students' emotional schemas scale. Journal of Clinical Psychology, Vol. 3, No. 11.

3. 1. Noorbala, Ahmad Ali, Mohammed Kazem and Bagheri Yazdi, Seyed Abbas. (1999). Prevalence of psychiatric disorders in Tehran. Wise Journal, Volume II, 4, 212-223.

4. Azizi, Ali Reza Shams, Jamal and Mirzaee, Azadeh. (2010). Investigate the relationship between distress tolerance, emotion regulation dependence on cigarettes students. Wise; (1) 13: 11-18.

1- Sadock, B. J. , \& Sadock, V. A.(2007). Kaplan \& Sadock's Synopsis of Psychiatry: Behavioral Sciences/Clinical Psychiatry. New York: Lippincott Williams \& Wilkins.

2- Sadock, B. J. ,Sadock, V. A., and Ruiz, P.(2009). Kaplan \& Sadock's Comprehensive Textbook of Psychiatry, 9th Edition. Lippincott Williams \& Wilkins.

3- Schramm, E. , Caspar, F., Berger, M. , (2006). Spezifische Psychotherapie für chronische Depression Cognitive Behavioral Analysis System of Psychotherapy nach McCullough. Nervenarzt 77(3), 355-371

4- Ravindran, A. V. , Griffiths, J. , waddell, C. , Anisman, H. , 1995. Stressful life events and coping styles in relation to dysthymia and major depressive disorder: Variations associated with alleviation of symptoms following Pharmacotherapy. Prog. Neuropsychopharmacol. Biol. Psydhiatry. 19, 637-653.

5- McFarland, B. R. , Klein, D. N. , 2005. Mental health service use by Patients with dysthymic disorder: treatment use and dropout in a 7 1/2-year naturalistinc follow-up study. Compr. Psychiatry 46, 246-253.

6- Miller, L. W., Norman, W. H., Dow, M. C., 1986. Psychosocial characteristics of double depression. Am. J. Psychiatry 143, 1042-1044.

7- Klein, D. N . , Taylor, E. B ., Dickstain,s. ,\& Harding,L.(1988). Primary-onest dysthymia: com pqrision whit primary nonbipolar nonchronic major depression on demographic,clinical, familial, personality, socioenvi romental characteristics and short term outcome. journal of Abnormal psychology, $97,387-398$.

8- Almaes, R. , Torgersen, S. ,(1989). Characteristics of patients with major depression in combination with dysthymic or cyclothymic disorders: Childhood and pr ecipitating events. Acta Psychiatr. Scand. 79, 11-18. 
9- Hewitt, C. E. , Perry, A. E., Adams, B., Gilbody, S. M., 2011. Screening and case finding for depression in offender populations: a systematic review of diagnostic properties. Journal of Affective Disorders 128, 72-82.

10- Alpert, J. \& Fava, M.(2004). Handbook of chronic depression. Diagnosis and therapeutic management. New York: Maca Pekker.

11- Klein, D. N., Riso, P. L., Donaldson, S. K., Schwartz, J. E., Anderson, R. L., Ouimette, P. C. , Lizardi, H. , Aronson, T. A.(1995). Family study of early-onset

12- Hughes, D. C. , DeMallie,D. , Blazer, D. G. ,1993. Dose age make a difference in the effects of physical health and social support the outcome of major depressive episode? American Journal of Psychiatry . 150, 728-733.

13- Woody, G. E. , Luborsky, L. , McClellan, A. T. , O’Brien, C. P. , Beck, A. T. , Blaine, J. , Herman, I. , \& Hole,A.(1983). Psychotherapy for opiate addicts: Does it help? Archives of General Psychiatry, 40, 1081-1086.

14- Young ,j. E . ,Klasko ,j. s. ,\&weishaar,M. E.(2003). Schema therapy:Apractitioner’s guide. New York: Guilford press.

15- Ustun,T. B. , Ayuso-Mateos, J. I. ,Chatterji,S. , Mathers, C.(2004). Global burden of depressive disorders in the year 2000. British Journal of Psychiatry. 188, 13-20.

16- Emanuel, A. S., Updegraff, J. A., Kalmbach, A. D. \& Ciesla, J. A. (2010), "The role of mindfulness facets in affective forecasting", Personality and Individual differences, 49,815-818

17- DeBruin, E, J., Topper, M., Muskens, Y, G, A, M., Bogels, S, M., \& Kamphuis, J, H. (2012). Psychometric Proprties Of Meditating and Non-Meditating Sample. Assessment,19,187-197.

18- Brambilla, F. , Musetti, C. , Taccini, C. , Fontanillas, J. , Guareschi-Cazzullo,A. ,(1989). Neuroendocrine investigation in children and adolescents with dysthymic disorders: The DST, TRH and clonidine Tests. J. Affective Disorder. 17, 279-284. 